\title{
Fractionation and Characterization of Natural Organic Matter from Certain Rivers and Soils by Free-Flow Electrophoresis
}

GEOLOGICAL SURVEY WATER-SUPPLY PAPER 1817-E 


\section{Fractionation and Characterization of Natural Organic Matter from Certain Rivers and Soils by Free-Flow Electrophoresis}

By J. A. LEENHEER and R. L. MALCOLM

ORGANIC SUBSTANCES IN WATER

GEOLOGICAL SURVEY WATER-SUPPLY PAPER 1817-E

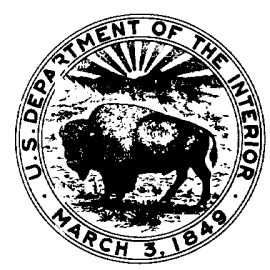




\section{UNITED STATES DEPARTMENT OF THE INTERIOR ROGERS C. B. MORTON, Secretary}

\section{GEOLOGICAL SURVEY}

V. E. McKelvey, Director

Library of Congress catalog-card No. 73-600209

For sale by the Superintendent of Documents, U. S. Government Printing Office Washington, D. C. 20402 - Price 35 cente (paper cover) Stock No. 2401-02400 


\section{CONTENTS}

$\begin{array}{lr}\text { Abstract } & \text { Page } \\ \text { Introduction } & \text { E1 } \\ \text { Methods and materials } & 1 \\ \quad \text { Sample preparation } & 3 \\ \text { Sample description } & \\ \quad \text { Separation procedure } & \\ \quad \text { Assay of fractions } & \\ \text { Results and discussion } & \\ \text { Conclusions } & \\ \text { References }\end{array}$

\section{ILLUSTRATIONS}

Figures 1-3. Graphs showing:

1. Organic-carbon and optical-density electrophoretic fractionation curves for organic materials from soil and from river water

2. Organic-carbon and polysaccharide electrophoretic fractionation curves for fulvic acid from soils

3. Organic-carbon and polysaccharide electrophoretic fractionation curves for dissolved organic materials from rivers

4. Infrared spectra of Fairbanks fulvic acid fractions _......

\section{TABLES}

TABLE 1. Percentage of polysaccharide carbon at the peak of the polysaccharide fractionation curve

2. Elemental analysis of Fairbanks fulvic acid fractions 


\title{
FRACTIONATION AND CHARACTERIZATION OF NATURAL ORGANIC MATTER FROM CERTAIN RIVERS AND SOILS BY FREE-FLOW ELECTROPHORESIS
}

\author{
By J. A. Leenheer and R. L. Malcolm
}

\begin{abstract}
Soluble river organic matter and soil fulvic acids from a variety of environmerts were compared by examining the free-flow electrophoretic fractionation curves of organic carbon, color, and polysaccharides. Significant amounts of virtually colorless organic material were found in both the soil and the river preparations. Polysaccharides comprised 20-75 percent of the colorless material in the soil fulvic acids but only 3.2-7.0 percent of the colorless material in the river preparations. A significant amount of polysaccharides was complexed with organic materials having negative charges. Amounts of polysaccharides were greater in the Fairbanks soil from Alaska than in the soils from North Carolina or Iowa, and they were greater in the Tahquamenon River in Michigan than in the two rivers in Florida; this suggests that polysaccharide degradation is slower in cooler environments.

For all of the organic preparations which were fractionated, the intensity of the yellow color increased as the charge on the organic anion increased. Highly colored, negatively charged organic material was fourd to be present in greater amounts in the subsurface spodic soil horizon of the Lakewood and Fairbanks soils than in the surface mollic horizon of the Macksburg soil.

Infrared spectroscopy and elemental analysis of four pooled fractions of the Fairbanks fulvic acid indicated increasing aromatic character with increasing negative charge. An increase in the carboxyl content with negative charge suggests the carboxyl group as the primary source of the negative charge.
\end{abstract}

\section{INTRODUCTION}

Similarities have been found between fulvic acid extracts from soils and the colored natural organic materials in many lakes and streams. Wilson (1959) held that colored organic matter in water is fulvic acid derived from soil organic matter. Because fulvic acid is the most water soluble of the extractable organic-matter fractions from soils, more fulvic acid than any other soil organic-matter fraction is likely to be found in water. Midwood and Felbeck (1968) found that over 80 percent of the carbon present in colored organic matter dissolved or suspended in pond water is in the fulvic acid fraction. They found the pond organic matter to be resistant to both chemical and biological degradation, as is characteristic of soil fulvic acids. Yellow organic acids of lake waters were named "humolimnic" acids by 
Shapiro (1957) to indicate their probable relation with the natural organic acids of the type found in soils.

Black and Christman (1963a) applied soil-science techniques developed for characterization of soil organic matter to the chemical characterization of colored organic materials in water. Through the use of ar qular-lightscattering data and ultraviolet spectroscopy, they found that the material responsible for color in water exists primarily in colloidal suspension. Data obtained from solubility relationships, chemical spot tests, and infrared absorption spectra indicated that fulvic acids found in surface waters are aromatic polyhydroxy methoxy carboxylic acids. In a study of organic extracts from some colored streams in western Washington, Christman and Ghassemi (1966) found substantial variation in the color-producing properties of organic materials in different streams. They assumed that the water did not contain substantial quantities of non-color-producing organic materials. Studies on the degradation of organic matter provided evidence for the presence of phenolic nuclei in the color macromolecula.

In the past, chemical characterizations of natural organic materials found in soils and water have often been performed on gross extracts called humic and fulvic acids. These acids are not specific compounds; rath $\cdot$, they are complex mixtures of organic polyelectrolytes. Thus, these humir and fulvic extracts frequently defied characterization because the mixturos were not fractionated into more homogeneous components prior to analysis. Recent advancements in gel-permeation chromatography and preparative electrophoresis now permit fractionation of humic and fulvic acids in aqueous media to be routinely performed prior to further analysis.

Until recently, preparatory electrophoretic methods were limited by such problems as adsorption interactions upon an electrolyte supporting curtain, inadequate cooling at high voltage and current, and small amornts of sample. High-resolution electrophoretic fractionations of organic-matter extracts were difficult to obtain when an electrolyte supporting medium such as filter paper was used in continuous electrophoresis. Adsorption of the organic material on the supporting media was the major hindrance, particularly when acidic electrolytes were used. Consequently, organic-matter extracts were often hydrolyzed prior to electrophoresis to produce constituents of greatly different mobilities which could be resolved (Johnson, 1959; Waldron and Mortensen, 1961). Clapp (1957) and Mortensen and Schwendinger (1963) resolved colorless soil polysaccharides from a more highly colored organic fraction of soil-water extracts.

The development of continuous free-flow electrophoresis has circumvented the adsorption problem. In this method, electrophoretic separations are carried out in a self-supported film of buffer between glass plates, and large amounts of sample can be fractionated in a relctively short time. Free-flow electrophoresis was found to be highly suitable for fulvic acid fractionations in aqueous media (Leenheer and Malcolm, 1973). 
This report compares free-flow electrophoretic fractionations of soil fulvic acids and soluble river organic materials from a variety of environments. Limited characterization of the polysaccharide constituents along with visible and infrared spectral analysis aid in the interpretations of the electrophoretic fractionations.

\section{METHODS AND MATERIALS SAMPLE PREPARATION}

The soil fulvic acids were extracted according to the following procedure. Organic matter was extracted from the soils by using $0.1 \mathrm{~N}$ sodium hydroxide under nitrogen to prevent auto-oxidation of the organic extract. The suspended clay was removed by centrifugation and filtration, and the humic acid was precipitated from the fulvic acid by acidifying the filtrate to $\mathrm{pH} 1$ with hydrochloric acid. The fulvic acids remaining in solution were dialyzed against distilled water for removal of the hydrochloric acid. Final purification of the fulvic acid was done by hydroxyl saturation in a hydroxylsaturated anion-exchange resin, followed by hydrogen saturation in a hydrogen-saturated cation-exchange resin. The fulvic acid solutions were freeze-dried for preservation.

The dissolved organic materials in surface waters were sep`rated and purified in the following manner. The sediment material was filtrated out by a partly clogged vinyl metricell membrane filter, the metallic cations were removed by using a hydrogen-saturated cation-exchange resin, and the water was eliminated by freeze-drying. Because the predominant anion in the waters selected for this study was the organic anion, removal of the inorganic anions was not necessary to obtain organic preparations having an ash content of 5 percent or less.

The freeze-dried fulvic acids and the organic materials extracted from river waters were usually dissolved simply by adding distiled water. However, if some of the organic material refused to go into solution, it was dissolved in a minimum amount of $0.1 \mathrm{~N}$ sodium hydroxide solution and then was hydrogen saturated by passage through a hydrogen-saturated cation-exchange resin. The organic-matter preparations used for electrophoretic fractionation were initially dissolved in water at con entrations of 10-20 milligrams per milliliter. The solutions were diluted 1:1 with the separation buffer to give final concentrations of 5-10 milligrams per milliliter.

\section{SAMPLE DESCRIPTION}

Fulvic acids were extracted from the spodic horizon of soils of the Fairbanks series, collected near Fairbanks, Alaska; from the spodic horizon of soils of the Lakewood series, collected near Wilmington, N.C.; and from the mollic horizon of soils of the Macksburg series, collected near Des Moines, Iowa. The spodic horizon is characterized by illuvial acc imulations of free sesquioxides and by metallo-organic saits and complexe of humic and fulvic acids which have been leached from the upper sections of the soil 
profile. The mollic horizon is the deep, darkly colored surface horizon found under grass vegetation, which is the source of the organic matter.

The river waters selected for this study were also in a variety of environments. A water sample was taken from Jane Green Creek near Melbourne, Fla., to examine the organic material in waters draining a hardwood cyprus swamp. The Sopchoppy River, sampled near Tallahassee, Fla., drains an upland area containing coniferous vegetatior: however, small areas of cyprus swamps also drain into the Sopchoppy River. Lastly, the Tahquamenon River was sampled at Newberry, Mich., to examine the organic material from a northern cedar and tamarack swamp.

\section{SEPARATION PROCEDURE}

In this study, the Brinkman Free-Flow Electrophoretic Separator (Model FF4) ${ }^{1}$ was used. The instrument and its method of operation have been described elsewhere (Brinkman Instrument Co., 1969). The mothodology and the applications of free-flow electrophoresis to the fractionation of natural organic materials were discussed in a paper by Leenheer and Malcolm (1973).

The separation buffer selected for this study was $0.16 \mathrm{M}$ phosphoric acid, which gave a $\mathrm{pH}$ of 2.2. The buffering capacity of this solution was not overcome even after 15 hours of continuous electrophoresis, and the $\mathrm{pH}$ was sufficiently low to give good fractionations based on isoelectric $\mathrm{pH}$ differences. The electrode rinse buffer was the same concentration as the separation buffer. The separation-buffer flow rate was about 100 milliliters per hour. The electric field strength was held at 450 volts $(30 \mathrm{v} / \mathrm{cm})$. Lastly, the temperature of each run was set at $10^{\circ} \mathrm{C}$, and the sample was injected into the separation chamber at the rate of about 6 milliliters per hour. A onehour electrophoresis run at the specified separation-buffer and sampleinjection flow rates produced 106 milliliters of sample diluted by the separation buffer. After the 106 milliliters was equally divided into 97 fractions, each fraction contained about 1.2 milliliters. A four-hour electrophoresis run produced sufficient volume in each fraction for determinations of organic carbon, polysaccharides, and color.

\section{ASSAY OF FRACTIONS}

The organic-carbon determination of the electrophoretic fractionation of the organic-matter preparations was made by monitoring $\mathrm{tl} \cdot \mathrm{o}$ organiccarbon parameter on an organic-carbon analyzer. Because the phosphoric acid buffer caused the $\mathrm{pH}$ of the fractions to be below 4.5 , inorganic carbon was absent from the fractions, and organic carbon could be dir ?ctly determined. Each individual organic-carbon determination was made on only 40 microliters of sample. Aliquots were taken from every other fraction of the 90 fractions except near the peaks of the organic-carbon curves, where

'Mention of a specific product is for identification only and does not constitute endorsement by the U.S. Geological Survey. 
determinations were made on every fraction for high resolution. A c cmplete determination of the organic-carbon electrophoretic fractionation required 2 hours or less.

Polysaccharide concentrations were monitored by a procedure used by Clapp (1957). In this procedure, the polysaccharides were hydrolized to the constituent sugars by sulfuric acid, and the sugars reacted with $a$-n aphthol to form a colored complex, which was measured by absorbance at 570 nanometers. Sucrose was used to determine the standard curve, and watersoluble starch was found to give equivalent results as the polysaccharide standard. The absorbance sample blanks of the colored fractions were subtracted from the sample absorbance to obtain the true absorbance values for sugars in the colored fractions.

The color of the electrophoretic fractions was determined by absorbance at 400 nanometers. Although natural organic materials do not exhibit maximums in the visible and ultraviolet absorbance spectra, 400 nanometers is the wavelength commonly selected for the measurement of color of organicmatter solutions.

More extensive characterization of the separates required removal of the buffer and drying of the samples. On the basis of the organic-carbon fractionation curve, the 90 fractions were pooled into four fractions for characterization. The phosphoric acid buffer was removed by dialysis against deionized water in 8-centimeter dialysis tubing for a period of 2 days. After desalting, the samples were freeze-dried to give fluffy watersoluble preparations suitable for analysis.

Infrared spectra of the four pooled fractions were run from 2 to 25 micrometers. Elemental analysis for carbon, hydrogen, oxygen, nitrogen, sulfur, and phosphorus and an ash determination were performed tv Huffman Laboratories, Inc., Wheatridge, Colo.

\section{RESULTS AND DISCUSSION}

The initial electrophoretic fractionations indicated that a large proportion of the organic matter extracted from both soils and rivers had little color. Figure 1 presents the optical-density (color) curves and the organiccarbon fractionation curves for the Fairbanks fulvic acid and the Jane Green Creek organic matter. Although the organic-carbon fractionation curves of the two preparations were greatly different, the color curves were very similar. For both preparations, the slightly charged fraction which peaks near the point of application only gives a slight absorbance for the color curve, and the color maximum at tube 52 does not correspond with any peak of the organic-carbon fractionation curve. Thus, color serves as a very poor index of organic-carbon concentration. Figure 1 indicates that color increases as the electrophoretic mobility and the ionic charge increase. The highly charged, colored fractions may be more aromatic than the fractions of lesser charge and color because light absorbance occurs in the pi 
electron system of organic compounds having conjugated double-bond systems.

The assumption by Christman and Ghassemi (1966) that river water does not contain substantial quantities of non-color-producing organic material does not appear to be valid for the Florida rivers of this study. This electrophoretic study indicates that the relationship between color and organic matter concentration is dependent on the ratios of the concentration to color of the individual organic constituents in solution. In data not presented here, the color was found to intensify slightly when the $\mathrm{pH}$ was

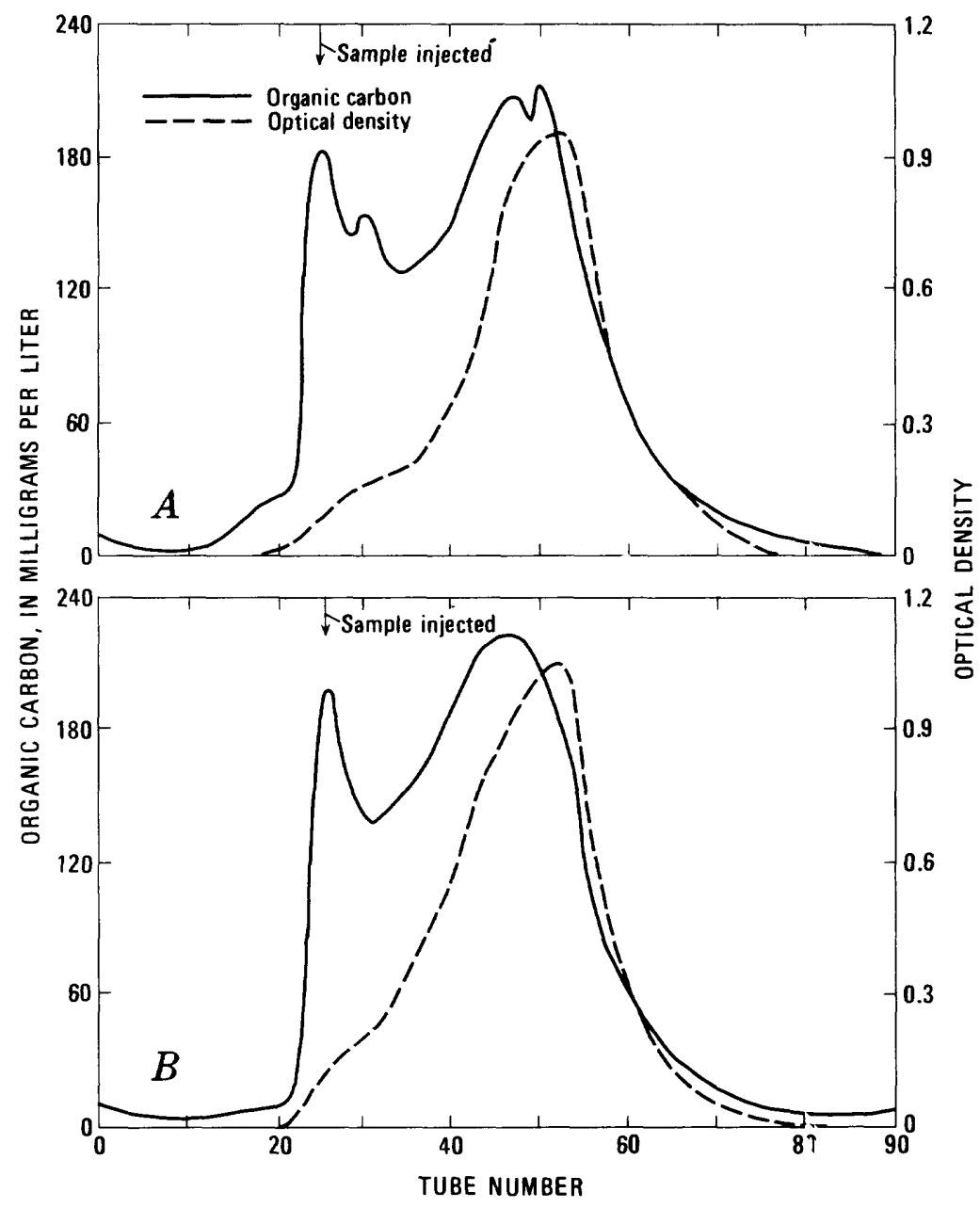

FIGURE 1. - Organic-carbon and optical-density electrophoretic fract: onation curves for organic materials from soil and from river water. $A$, Fairbanks soil fulvic acid, Alaska; $B$, Jane Green Creek, Fla. 
raised from 2.2 to 7.0 by addition of sodium hydroxide to the phosphoric acid buffer. The absorbance of the entire color curve increased by about 8 percent for the organic matter from Jane Green Creek. The effect of $\mathrm{pH}$ on color was also noted by Black and Christman (1963b), who at'ributed the increase in color to the greater amount of dispersion of the organic matter at higher $\mathrm{pH}$ levels.

The main comparisons of this study are graphically illustrated in figures 2 and 3. Figure 2 presents the organic-carbon and polysaccharide elec-

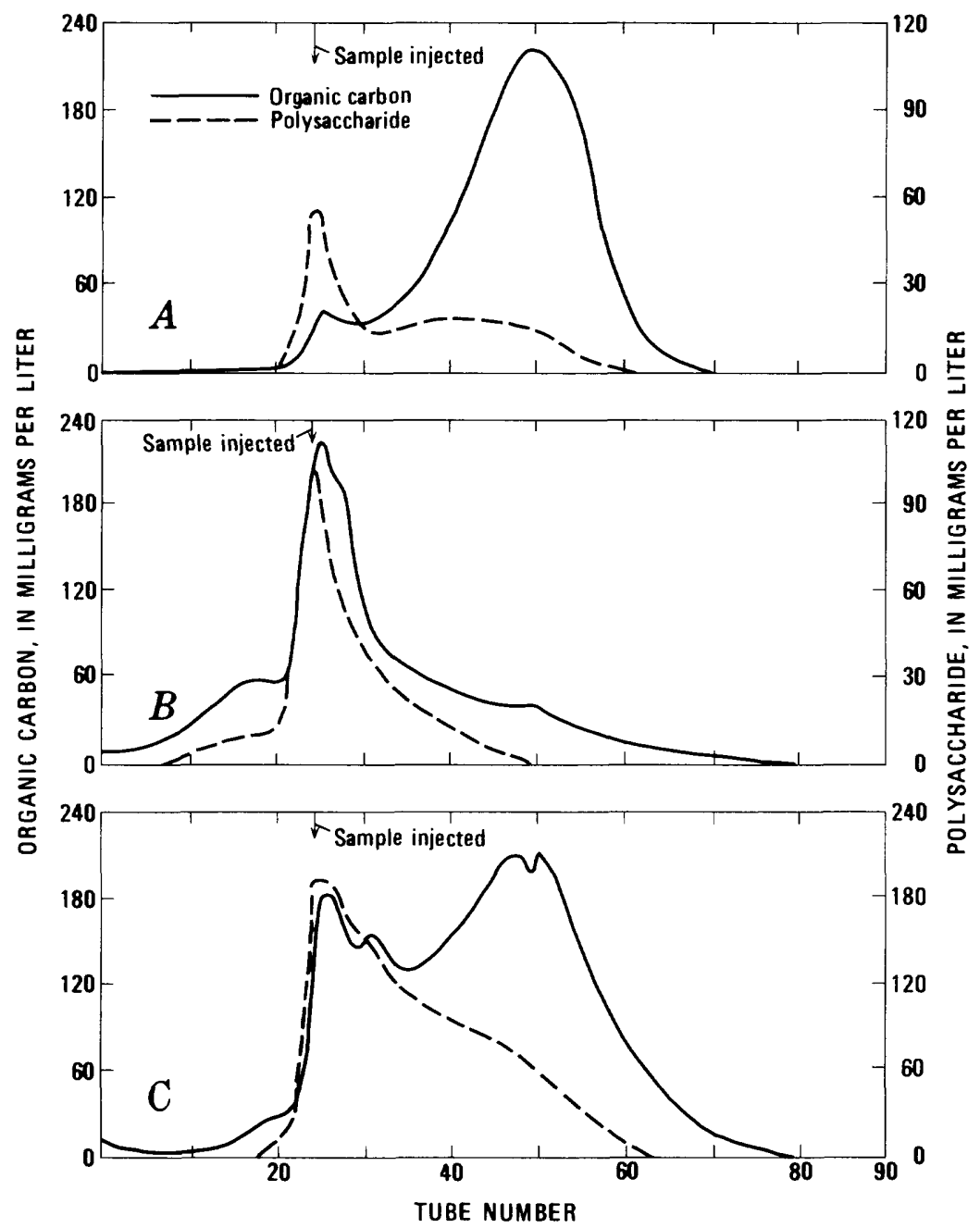

FIGURE 2. - Organic-carbon and polysaccharide electrophoretic fractionation curves for fulvic acid from soils. $A$, Lakewood series, North Carolina; $B$, Mackshurg series, Iowa; $C$, Fairbanks series, Alaska. 
trophoretic fractionations of the soil fulvic acids, and figure 3 presents the same parameters for the river preparations. The polysaccharide concentration is based on milligrams per liter of sucrose equivalents.

The organic-carbon curves of the fulvic acid fractionations lave a few features in common, but in the main, they differ greatly. All three have a slightly charged, slightly colored fraction whose peak at tute 25 corresponds to the main peak of the polysaccharide fractionation, and they all have a highly charged, highly colored fraction which peaks at tul is 46-50.

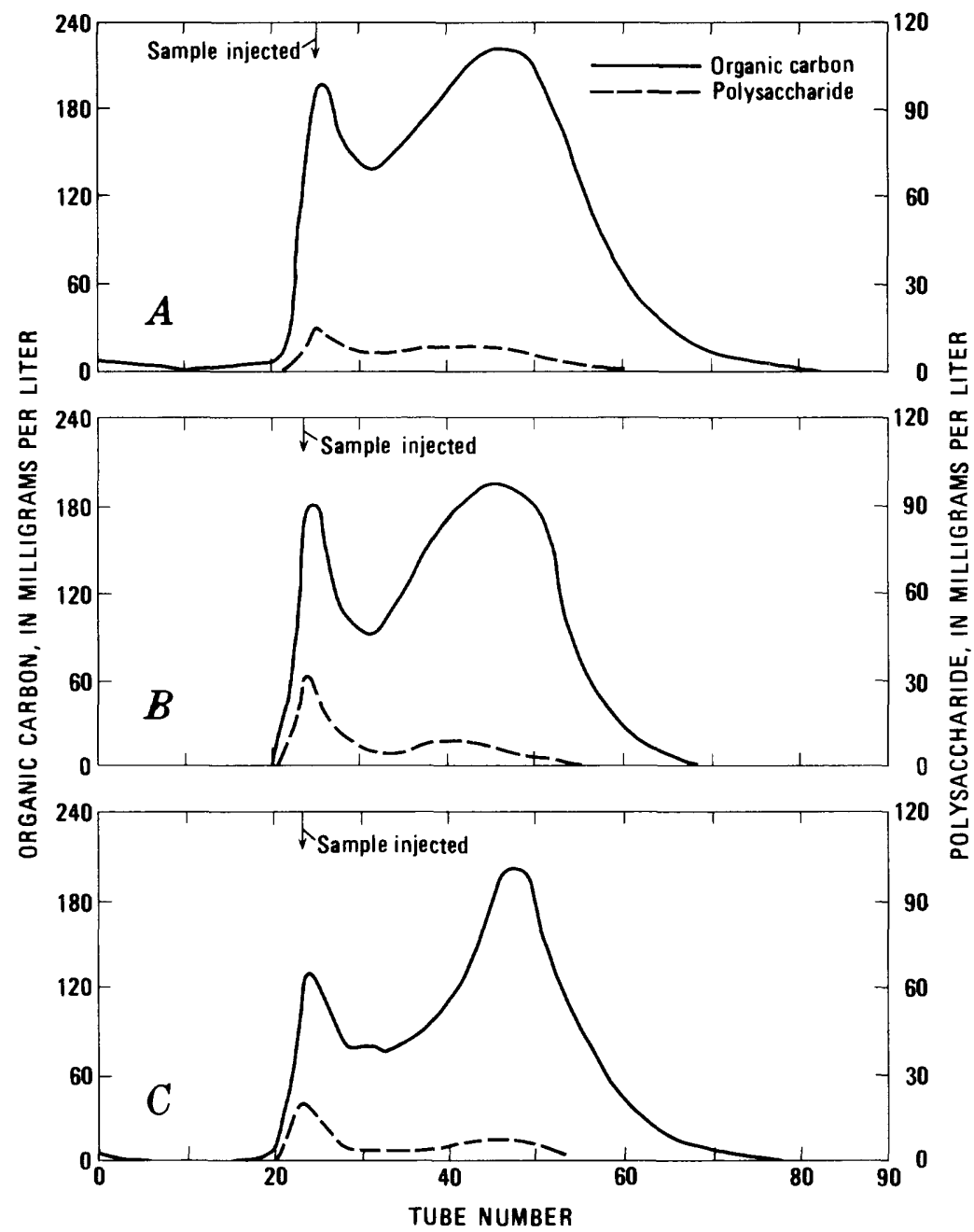

FIGURE 3. - Organic-carbon and polysaccharide electrophoretic fractionation curves for dissolved organic materials from rivers. $A$, Jane Green Creek, Fla.; $B$, Sopchoppy River, Fla.; $C$, Tahquamenon River, Mich. 
The relative distribution of organic carbon, however, differs greatly for the three fulvic acid preparations.

The Lakewood fulvic acid (fig. $2 A$ ) is characterized by its large amount of colored, charged material, which peaks at tube 49. Table 1 indicates that nearly three-quarters of the organic carbon at the polysaccharide maximum is bound in polysaccharides at tube 24 . The percentage carbon in polysaccharide was estimated to be 40 percent, the same as in glucese. The slightly charged peak of the Lakewood fulvic acid has the highest polysaccharide percentage in comparison with the other fulvi? acids. However, inspection of the curves in figure 2 shows that the total amount of polysaccharides in the Lakewood preparation is the lowest of the three preparations because of the small amount of organic carbon in the slightly charged fraction. Comparisons of peak areas under the polysaccharide fractionation curve show that more than half of the polysaccharide material appears to be complexed with charged organic materials. Secondary polysaccharide peaks appear at tubes 40 and 46 . In an infrared study of the polysaccharide constituents in fulvic and humic acids, Tan and Clark (1969) also found chemically bonded polysaccharides in humic materials.

TABLE 1. - Percentage of polysaccharide carbon at the peak of the poly:accharide fractionation curve

\begin{tabular}{|c|c|}
\hline Preparation & $\begin{array}{l}\text { Polysaccharde carbon } \\
\text { (percent of total carbon) }\end{array}$ \\
\hline \multicolumn{2}{|l|}{ Soil fulvic acids: } \\
\hline Lakewood soil & 74.7 \\
\hline 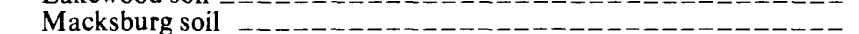 & 20.0 \\
\hline Fairbanks soil & 42.6 \\
\hline \multicolumn{2}{|l|}{ Soluble river organic matter: } \\
\hline Jane Green Creek & 3.2 \\
\hline Sopchoppy River & 5.6 \\
\hline Tahquamenon River & 7.0 \\
\hline
\end{tabular}

Organic material with greatly different charge, color, and polysaccharide characteristics is seen in the Macksburg fulvic acid (fig. $2 B$ ). Most of the material possesses a slight negative charge and has little color, but a significant amount of material is positively charged, as indicated to the left of the point of application. The polysaccharide percentage is only 20 percent at tube 24 (table 1). The total polysaccharide content is greater than in the Lakewood fulvic acid because of the large quantity of slightly charged material where most of the polysaccharides occur. The characteristic peak at tube 49 shows up only as a slight shoulder in this preparation.

By far the most diversity is found in the electrophoretic fractionation of the Fairbanks fulvic acid (fig. 2C). Four distinct peaks and a prsitively charged shoulder are found in the fractionation. A polysaccharide content of 42.6 percent (table 1) at tube 25 and substantial quantities of negatively 
charged complexed polysaccharides give this preparation by far the highest total polysaccharide content. The twin peaks at tubes 47 and 50 of the organic-carbon curve were also found in two subsequent runs of this fulvic acid.

The electrophoretic fractionations of the organic materials extracted from river waters exhibited much less diversity. The organic-carbon curves in figure 3 show two maximums for each preparation: organic material of slight color and charge which peaks near the point of application, and colored organic material of high negative charge which peaks at tubes 46-58. These characteristic peaks appear near the same pc sitions as the peaks in the fulvic acid preparations.

The organic-carbon fractionations from Jane Green Creek and the Sopchoppy River are very similar in appearance (fig. $3 A$ and $B$ ). The geographical proximity and climatic similarities of these two streams may give rise to closely related types and distributions of organic materials. The biggest apparent difference from fulvic acid preparations is tr- $\cdot$ low level of polysaccharides in the river preparations. Table 1 lists only 3.2-7.0 percent polysaccharide carbon at the maximums of the polysaccharide fractionations for the river preparations, whereas the polysaccharide carbon ranges from 20 to 75 percent for the fulvic acids.

The fractionation of the dissolved organic material from the Tahquamenon River (fig. $3 C$ ) differed from the Florida streams ir that the peak representing the colored material of high negative charge was resolved into a more distinct peak. This could be an indication of less diversity in type of organic materials in the Michigan river. Also, the polysaccharide content was the highest of the three streams.

The Fairbanks fulvic acid was selected for additional chara?terization by infrared and elemental analysis because its fractionation cur'e showed the major characteristic peaks common to the other preparations plus peaks at tubes 31 and 50, which were not common to the other preparations. A largescale fractionation was performed on more than 400 milligrams of material. After fractionation, tubes $22-28,29-35,36-48$, and $49-65$ were respectively pooled and numbered 1 through 4; the four pooled factions were desalted by dialysis, and the organic material in solution was freeze-dried. Each pooled fraction yielded abundant material for both infrared and elemental analysis. The infrared spectra of the four fractions are given in figure 4.

Various functionalities were ascribed to the different absorption bands. The strong absorption band at $2.90 \mu \mathrm{m}$ (micrometers) is due to hydroxyl stretching, the shoulder band at $3.40 \mu \mathrm{m}$ is due to aliphatic carbon-hydrogen stretching, and the broad band at $3.7 \mu \mathrm{m}-4.0 \mu \mathrm{m}$ is due to hyd ogen-bonded hydroxyl indicative of dimeric carboxyl groups. The carbony' of esters and carboxylic acids is at $5.80 \mu \mathrm{m}$, the carboxylate ion symmetrical stretch is at $6.10 \mu \mathrm{m}$, the nitrogen-hydrogen-bond deformation of mcnosubstituted 


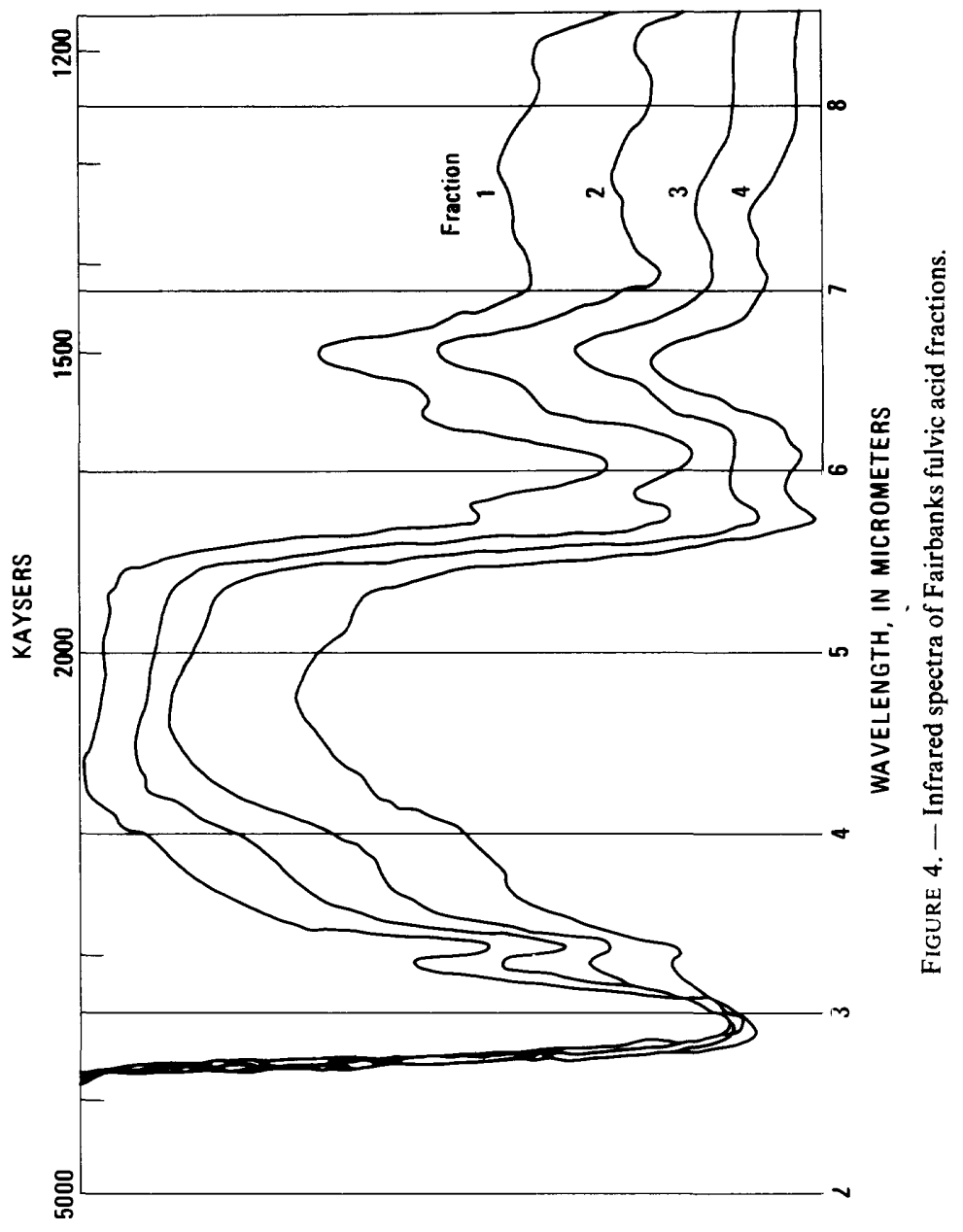


amides is at $6.40 \mu \mathrm{m}-6.50 \mu \mathrm{m}$, and the carboxylate ion asymmetrical stretch is at $7.1 \mu \mathrm{m}-7.2 \mu \mathrm{m}$.

Several changes in functional-group content were noted from fraction 1 to fraction 4. Firstly, aliphatic hydrogen at $3.40 \mu \mathrm{m}$ is greater in fractions 1 and 2 than in fraction 3 and especially in fraction 4 , where tr 9 band is present only as a weak shoulder. This suggests that fractions 1 and 2 , which possess a slight charge, have a much greater aliphatic nature than fractions 3 and 4 , which have a higher charge. Secondly, the broad hyc'rogen-bonded hydroxyl band at $3.7 \mu \mathrm{m}-4.0 \mu \mathrm{m}$ becomes progressively stronger from fraction 1 to fraction 4 , suggesting that the negative charge in tr $\%$ higher fractions may originate from the greater carboxyl content.

Thirdly, although changes occurred in the carbonyl, carboxyl, and carboxylate bands at $5.80 \mu \mathrm{m}, 6.10 \mu \mathrm{m}$, and $7.1 \mu \mathrm{m}-7.2 \mu \mathrm{m}$, no special significance can be ascribed to them because the preparations were not found to be hydrogen saturated after dialysis. This indicates that separates should be run through a hydrogen-saturated cation-exchange column after dialysis. The ratio of the $5.80 \mu \mathrm{m}$ band to the $6.10 \mu \mathrm{m}$ band is mainly due to the ratio of carboxylic acid to carboxylate salt in the sample.

Lastly, the band at $6.40 \mu \mathrm{m}-6.50 \mu \mathrm{m}$, which indicates monosubstituted amides, is strongest in fraction 1 and progressively decreases until it is completely absent in fraction 4. Mortensen and Schwendinger (1963) also noted this band in an electrophoretic separate of soil polysaccharides. They ascribed this nitrogen functionality to amino sugars and protein contaminants of soil polysaccharides. Such nitrogenous groups a re protonated at low $\mathrm{pH}$ values and neutralize the negatively charged group; this process gives rise to Zwitter ions, which have low electrophoretic mobility, as is found in fraction 4.

The elemental analysis of fractions 1 through 4 is given in table 2 . The analyses for carbon, hydrogen, oxygen, and nitrogen are adjusted to an ashfree basis. The total elemental analysis is slightly greater than 100 percent because the oxygen values are high. Inorganic oxygen in the ash was determined along with organic oxygen. Therefore, the oxygen analyses have limited value because of ash interference. However, the carbon and hydrogen analyses clearly indicate increasing aromatic character from fraction 1 to fraction 4 as the carbon-hydrogen ratio increases from 7.8 in fraction 1 to 13.3 in fraction 4 .

\section{CONCLUSIONS}

Both soil fulvic acids and organic materials dissolved in river waters commonly contain substantial quantities of organic material which possess no color and charge. A large percentage of the colorless material was determined to be polysaccharides for the soil fulvic acids, but only a small percentage of the colorless material in the river extracts was found to be polysaccharides. This difference in relative polysaccharide abundance may 
TABLE 2. - Elemental analysis (in percent) of Fairbanks fulvic acid fractions

[Percentages of elements are adjusted to an ash-free basis]

\begin{tabular}{|c|c|c|c|c|c|c|c|}
\hline \multirow[b]{2}{*}{ Fraction } & \multicolumn{6}{|c|}{ Element } & \multirow[b]{2}{*}{ Ash } \\
\hline & Carbon & Hydrogen & $\begin{array}{l}\text { Ratio of } \\
\text { carbon to } \\
\text { hydrogen }\end{array}$ & Oxygen & Nitrogen & Total & \\
\hline 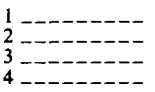 & $\begin{array}{l}46.15 \\
46.90 \\
51.59 \\
51.92\end{array}$ & $\begin{array}{l}5.92 \\
5.66 \\
4.46 \\
3.95\end{array}$ & $\begin{array}{r}7.8 \\
8.3 \\
11.6 \\
13.3\end{array}$ & $\begin{array}{l}46.06 \\
47.21 \\
43.08 \\
48.22\end{array}$ & $\begin{array}{l}2.63 \\
2.56 \\
2.67 \\
2.09\end{array}$ & $\begin{array}{l}100.8 \\
102.3 \\
101.8 \\
106.1\end{array}$ & $\begin{array}{r}6.97 \\
7.05 \\
7.19 \\
14.52\end{array}$ \\
\hline
\end{tabular}

be due to microbial rates of polysaccharide degradation being slcwer in soils than in rivers, or it may simply point to different organic-extraction efficiencies. However, studies of biochemical oxygen demand have shown that polysaccharides in solution in rivers are immediately available for microbial degradation.

Climate and soil type may have significant effects on the polysaccharide content and the type of organic matter. In the frigid environment of the Fairbanks soil in Alaska, where microbial degradation of orgaric material in the spodic soil horizon is slow on an average yearly basis, the polysaccharide content was high. In the spodic horizon of the Lakewood soil in North Carolina, the polysaccharide content was much lower. The rate of microbial polysaccharide degradation may also be a factor in the river preparations, because the Tahquamenon River in northern Michigan had a greater polysaccharide content than did the Florida streams.

The differences in the electrophoretic fractionation curves for fulvic acid preparations from different soil horizons indicate that the highly colored organic material of high negative charge is leached from the surface horizon and accumulates in the spodic horizon. Some of this material is probably carried into lakes and streams, where it comprises the primary organic colorative agent. Very little of the colored, charged material w?s found in the fulvic acid from the surface mollic horizon of the Macksh 'rrg soil in Iowa.

Infrared and elemental analyses show increasing aromatic che racter with increasing negative charge for the Fairbanks fulvic acid. An inc"ease in the carboxyl content with negative charge indicates the carboxyl g ooup as the primary source of the negative charge.

Soil fulvic acid and organic materials dissolved in river waters are dynamic mixtures whose composition at any certain time depends on variables such as the type and quantity of source materials, the rates of microbial degradation, the stability of intermediate degradation products, and the solubility properties of all the components taken together. Free-flow electrophoresis is one technique for fractionating complex natural organic mixtures on the basis of electrical charge so the various fractions can be studied individually for a more complete characterization. 


\section{REFERENCES}

Black, A. P., and Christman, R. F., 1963a, Characteristics of colored surface waters: Am. Water Works Assoc. Jour., v. 55, no. 6, p. 753-769.

1963b, Chemical characteristics of fulvic acids: Am. Water Works Assoc. Jour., v. 55, no. 7, p. 897-912.

Brinkman Instrument Co., 1959, Electrophoretic Separator Model FF4 instrument manual: Westbury, New York, 17 p.

Christman, R. F., and Ghassemi, M., 1966, Chemical nature of organic color in water: Am. Water Works Assoc. Jour., v. 58, no. 6, p. 723-741.

Clapp, C. E., Jr., 1957, High molecular weight water-soluble muck; isolation and determination of constituent sugars of a borate complex-forming polysaccharide en vloying electrophoretic techniques; Cornell University Ph. D. dissertation, Dissert. Abs., v. 17, p. 963-964.

Johnson, H. H., 1959, Electrophoretic separation of acid-resistant components, part 1 of Soil organic matter: Soil Sci. Soc. America Proc., v. 23, p. 293-295.

Leenheer, J. A., and Malcolm, R. L., 1973, Preparative free-flow electrophoresi` as a method of fractionation, purification, and characterization of natural organic m?terials: U.S. Geol. Survey Water-Supply Paper $1817-$ D, 14 p.

Midwood, R. B., and Felbeck, G. T., Jr., 1968, Analysis of yellow organic matter from fresh water: Am. Water Works Assoc. Jour., v. 60, no. 3, p. 357-366.

Mortensen, J. L., and Schwendinger, R. B., 1963, Electrophoretic and spectroscopic characterization of high molecular weight components of soil organic mat ${ }^{*}$ : $:$ Geochim. et Cosmochim. Acta, v. 27, p. 201-208.

Shapiro, J., 1957, Chemical and biological studies on the yellow organic acids of lake water: Limnology and Oceanography, v. 2, p. 161-169.

Tan, K. H., and Clark, F. E., 1969, Polysaccharide constituents in fulvic and humic acids extracted from soil: Geoderma, v. 2, p. 245-255.

Waldron, A. C., and Mortensen, J. L., 1961, Electrophoretic separation of organic components, part 2 of Soil nitrogen complexes: Soil Sci. Soc. America Proc., v. 25, p. $29-32$.

Wilson, A. L., 1959, Determination of fulvic acids in water: Jour. Appl. Chemistry, v. 9, p. 501-512.

U.S. GOVERNMENT PRINTING OFFICE: 1973 0.-543-576/2 